\title{
Use of Methotrexate in the Treatment of Moderate to Severe Plaque Psoriasis in France: A Practice Survey
}

\author{
Anne-Claire Fougerousse (1D) \\ Laure Mery-Bossard ${ }^{2}$ \\ Josiane Parier ${ }^{3}$ \\ Charles Taieb (D) ${ }^{4}$ \\ Antoine Bertolotti ${ }^{5,6}$ \\ Francois Maccari ${ }^{3}$

\section{On behalf of GEM ResoPso}

'Dermatology Department, Hôpital d'Instruction des Armées Bégin, Saint Mandé, 94160, France; ${ }^{2}$ Dermatology Department, Centre Hospitalier Intercommunal Poissy Sant Germain en Laye, Saint-Germain-en-Laye, 78100, France; ${ }^{3}$ Private Practice, La Varenne Saint Hilaire, Saint-Maur-des-Fossés, 94210, France; ${ }^{4}$ European Market Maintenance Assessment, Patients Priority Department, Fontenay sous-Bois, France; ${ }^{5}$ Infectious Diseases and Dermatology Department, Centre Hospitalier Universitaire de la Réunion, Saint Pierre, La Réunion, France; 6 Inserm CICl4I0, Centre Hospitalier

Universitaire de la Réunion, Saint Pierre, La Réunion, France
Correspondence: Anne-Claire Fougerousse Dermatology Department, Hôpital d'Instruction des Armées Bégin, 69 Avenue de Paris, Saint Mandé, 94160, France

$\mathrm{Tel}+33143985000$

$\mathrm{Fax}+331439849$ I5

Email ac.fougerousse@gmail.com
Purpose: To evaluate the modalities of methotrexate prescription for moderate to severe psoriasis by dermatologists in France.

Patients and Methods: We performed a national online practice survey between October and December 2020.

Results: A total of 254 dermatologists responded, 237 reported prescribing methotrexate for moderate to severe psoriasis in adults, of which $57 \%$ as a first line systemic treatment. Nineteen percent reported performing a test dose at the initiation of treatment. Methotrexate was prescribed orally in $54.7 \%$ of cases, subcutaneously in $44.8 \%$ of cases and intramuscularly in $0.4 \%$ of cases. The initial weekly dose of methotrexate was $<15 \mathrm{mg}$ for $30 \%$ of the dermatologists and $\geq 15 \mathrm{mg}$ for $70 \%$ of them. Two hundred and three dermatologists had already change the route of administration for methotrexate from the oral to injectable form due to poor tolerance (48.3\%), lack of efficacy (35\%) or lack of compliance (16.7\%). Two hundred thirty-four dermatologists $(98.7 \%)$ reported prescribing folic acid with methotrexate, and 79.3\% reported prescribing tests evaluating the risk of hepatic fibrosis. Forty-three percent of dermatologists have not initiated or have reduced their prescriptions since the beginning of the pandemic of COVID-19. Prescribing patterns were different according to the type of practice (private practice versus hospital/mixed practice).

Conclusion: Methotrexate is used by the majority of dermatologists interviewed for moderate to severe psoriasis in adults, with heterogeneity of practices.

Keywords: psoriasis, methotrexate, practice survey, dermatologists

Adult psoriasis is a frequently occurring chronic inflammatory dermatosis, the prevalence of which is estimated to be $4.4 \%$ in France. ${ }^{1}$ Moderate to severe forms, defined by a Psoriasis Activity and Severity Index (PASI) score $>10$, an affected skin surface $>10$, a Dermatology Life Quality Index (DLQI) score $>10$, or the involvement of particular locations (palms and soles, scalp, face, genital area, nails, etc.) justify prescription of a systemic treatment. ${ }^{2}$ Methotrexate is the firstline systemic treatment recommended in France. ${ }^{3}$ Surveys of international practice have highlighted heterogeneity in the prescription of methotrexate for this indication. ${ }^{4,5}$ Herein, we evaluate the modalities of methotrexate prescription for moderate to severe psoriasis by dermatologists in France.

\section{Patients and Methods}

We conducted a practice survey of Reso member dermatologists. Reso gathers more than 700 French dermatologists [ie nearly one French dermatologist out of 4]. 
These dermatologists work exclusively in hospitals, exclusively in private practice or in a mixed practice. They were asked by email to answer a digital questionnaire between October and December 2020. In the invitation email to participate in the project, each doctor had to confirm his or her agreement to participate in order to access the online questionnaire.They were under no obligation to respond and were not paid for it.

\section{Questionnaire}

The questionnaire was developed by dermatologists and a physician specialist in public health. It collected the age of the dermatologist, the length of the practice, the mode of practice (hospital, private or mixed), whether consultation dedicated to psoriasis is offered, and the prescription of methotrexate for adult psoriasis. It collected information on the methods of prescribing methotrexate, including the method of administration, dose, concomitant prescription of folic acid, monitoring methods, as well as the impact of the COVID-19 pandemic on prescriptions. The reasons for not prescribing methotrexate were collected for dermatologists who stated that they did not prescribe methotrexate for this indication.

For this type of study, French regulations do not require submission to an ethics committee as this study does not enter the field of the deliberation $n^{\circ} 2018-154$ of the 3rd of May 2018 (JORF $n^{\circ} 0160$ of the 13th of July 2018).

\section{Statistics}

Quantitative data are expressed as the average \pm standard deviation (SD), and qualitative data are expressed as percentages (\%). Means were compared using Student's $t$-test, and frequencies were compared using Chi-square test. A value of $p<0.05$ was considered statistically significant. Statistical analyses were performed using R software version 3.5.1.

\section{Results}

\section{Characteristics of Dermatologists}

Two hundred fifty-four dermatologists answered the questionnaire, representing $7.6 \%$ of French dermatologists [source JO Sénat du 11/12/2014 - page 2726]. The average length of practice was 18.9 years; $74(29.1 \%)$ worked in hospitals, $93(36.6 \%)$ in private practice and $87(34.2 \%)$ in a mixed practice; and $71(27.9 \%)$ offered consultation dedicated to psoriasis.

\section{Prescription of Methotrexate}

Two hundred thirty-seven dermatologists (93.3\%) reported prescribing methotrexate for moderate to severe psoriasis in adults. This proportion was $100 \%$ for dermatologists with hospital activity and $90 \%$ for those in private or mixed practices.

Seventeen dermatologists declared themselves to be non-prescribers. Among these physicians, 9 were in private practice, and 8 were in a mixed practice. Reasons given for non-prescription included fear of side effects $(n=8)$, lack of experience $(n=7)$, and dearth of eligible patients $(n=2)$.

\section{Prescription Modalities}

Among prescribers, 57\% stated that they prescribed methotrexate as a first line systemic treatment for adult psoriasis, $29 \%$ as a second line treatment and $14 \%$ as a third line treatment or less frequently. Dermatologists estimated the percentage of their moderate to severe psoriatic patients treated with methotrexate to be $36.2 \%$.

Forty-six dermatologists (19\%) reported that they perform a test dose at the initiation of treatment. Methotrexate was prescribed orally in $54.7 \%$ of cases, subcutaneously in $44.8 \%$ (pen, $36.1 \%$; syringe, $8.7 \%$ ), and intramuscularly in $0.4 \%$ of cases. The proportion of patients judged to be autonomous in carrying out the injections was $65.4 \%$. The initial weekly dose of methotrexate was less than $15 \mathrm{mg}$ for $30 \%$ of the dermatologists $(7.5 \mathrm{mg}: 7.6 \%$; $10 \mathrm{mg}$ : $16 \%$; and $12.5 \mathrm{mg}: 6.7 \%)$ and $\geq 15 \mathrm{mg}$ for $70 \%$ (15 mg: $51.9 \%$; $17.5 \mathrm{mg}: 7.1 \%$; $20 \mathrm{mg}: 9.7 \%$; $22.5 \mathrm{mg}: 0.4 \%$; and $25 \mathrm{mg}$ : $0.4 \%$ ). The time elapsing between dermatologists prescribing and evaluating the efficacy of methotrexate was less than 6 weeks for $9 \%$ ( 2 weeks: $0.4 \%$; 4 weeks: $8.4 \%$ ), from 6 to 8 weeks for $13 \%$ (6 weeks: $4.6 \%$; 8 weeks: $8 \%$ ) and greater than or equal to 10 weeks for $78 \%$ (10 weeks: $1.3 \% ; 12$ weeks: $30.4 \%$; and 16 weeks: $46.8 \%$ ). Two hundred and three dermatologists $(86 \%)$ stated that they had already changed the route of administration for methotrexate (from the oral to injectable form) due to poor tolerance $(48.3 \%)$, lack of efficacy $(35 \%)$ or lack of compliance (16.7\%).

In the event of a therapeutic response being deemed insufficient, 40 dermatologists (16.9\%) declared changing to subcutaneous administration, $20(8.4 \%)$ changing treatment and 177 dermatologists (74.7\%) to increasing the dose of methotrexate. Of these changes, the adjustment steps were $2.5 \mathrm{mg} /$ week in $54.9 \%$ of cases, $5 \mathrm{mg} /$ week in 
$41.8 \%$ of cases, and other in $3.4 \%$ of cases. In the case of digestive side effects, 172 dermatologists (72.6\%) reported switching to subcutaneous administration, $29(12.2 \%)$ to decreasing the dosage of methotrexate, and $36(15.2 \%)$ to changing treatment. In cases of asthenia, 122 dermatologists $(51.5 \%)$ reported reducing the dose of methotrexate, 87 (36.7\%) changing treatment, and 28 (11.8\%) switching to subcutaneous administration.

Two hundred thirty-four dermatologists (98.7\%) reported prescribing folic acid with methotrexate. The dose was $5 \mathrm{mg} /$ week for 59 dermatologists (24.9\%), $10 \mathrm{mg} /$ week for $134(56.5 \%)$ and more than $10 \mathrm{mg} /$ week for 44 (18.6\%). The recommended day of use was the day after taking methotrexate for 24 dermatologists (10.1\%), 48 hours after taking methotrexate for 204 dermatologists $(86.1 \%)$, and every day except for the day of methotrexate use for 9 dermatologists (3.8\%).

One hundred eighty-eight dermatologists (79.3\%) stated that they prescribed tests evaluating the risk of hepatic fibrosis, including Fibrotest ${ }^{\circledR}$ for 25 (13.3\%), pro-collagen III assay for $110(58.5 \%)$ and Fibroscan for 132 (70.2\%).

Since the start of the COVID-19 pandemic, 128 dermatologists $(54 \%)$ reported that their methotrexate prescriptions for psoriasis had remained stable, 71 (30\%) that they had decreased, and $3(1.3 \%)$ that they had increased. Twenty-eight (11.8\%) reported that they had not initiated methotrexate since the beginning of the pandemic.

Prescribing patterns by type of practice are shown in Table 1.

\section{Discussion}

The results of this survey underline the heterogeneity of practices in the prescription of methotrexate in moderate to severe psoriasis in adult patients in France. In fact, even though almost all dermatologists questioned used methotrexate for moderate to severe psoriasis in adults, the methods of prescription vary, apart from to the association with folic acid supplementation, which is almost systematic.

Only slightly more than one-half of dermatologists questioned indicated that they prescribe methotrexate as a firstline systemic treatment for moderate to severe psoriasis, whereas it is the first-line systemic treatment recommended in France. ${ }^{3}$ A fifth of dermatologists questioned stated that they perform a test dose, which is currently no longer compulsory $^{3}$ but may be useful in fragile patients. ${ }^{6,7}$ Almost two-thirds of dermatologists questioned start at a dose between 7.5 and $15 \mathrm{mg} /$ week, in accordance with French recommendations. ${ }^{3}$ However, a high cumulative dose during the first month of treatment (between 60 and $75 \mathrm{mg}$ ) was associated with improved efficacy in one study, ${ }^{8}$ while an initial dose of $15 \mathrm{mg} /$ week was proposed in some recommendations. ${ }^{7,9}$ The oral route of administration is preferred, although recent data have shown better efficacy and tolerance with a subcutaneous route of administration in a cohort of German patients. ${ }^{9}$ Even though the different recommendations agree on the need for folic acid supplementation, ${ }^{3,7,10}$ prescription modalities differ: while there are currently no British recommendations, ${ }^{10}$ a daily supplementation, except if methotrexate is administered concomitantly is suggested by American recommendations ${ }^{7}$ and a $5 \mathrm{mg}$ supplementation, 24h after the intake of methotrexate, is suggested by French recommendation. ${ }^{3}$ The time taken to evaluate the efficacy of treatment is more than 10 weeks for $78 \%$ of dermatologists, consistent with the kinetics of the molecule. ${ }^{3,7}$ The vast majority of dermatologists interviewed stated that they monitor the risk of hepatic fibrosis upon methotrexate use by dedicated testing. This risk remains debated since meta-analyses have yielded contradictory results; the cumulative dose of methotrexate has not been systematically identified as a risk factor, in contrast to diabetes, alcoholism and obesity. ${ }^{11,12}$ The COVID-19 pandemic has impacted the prescription of methotrexate among the dermatologists questioned, since $43 \%$ of them have not initiated or have reduced their prescriptions since the beginning of the pandemic. However, data have highlighted the absence of a seriously increased risk of COVID-19 in those undergoing systemic treatment for psoriasis, whether in the initiation or maintenance phase of treatment. ${ }^{13}$ It might be useful to vaccinate against COVID-19 before initiating methotrexate treatment, particularly in patients at risk of severe COVID-19, as there is a lower vaccine response in patients on this treatment. ${ }^{14}$

For the analysis, we grouped dermatologists in mixed and hospital-based practices together, as practising in a hospital environment in France allows access to the primary prescription of certain psoriasis treatments (cyclosporine and biotherapy). This study highlights differences in practice according to prescribing patterns. Dermatologists in hospital and mixed practice more frequently prescribe methotrexate as a first line systemic treatment at a higher initial dosage, more often in the form of subcutaneous pens, and evaluate their patients later. This may reflect a greater habit of methotrexate use. Their patients are more autonomous in performing subcutaneous injections, likely because 
Table I Results by Mode of Practice (Hospital and Mixed Practice/Private Practice)

\begin{tabular}{|c|c|c|c|}
\hline Study Population & $\begin{array}{l}\text { Hospital/Mixed Practice } \\
(n=161)\end{array}$ & $\begin{array}{l}\text { Private Practice } \\
(n=93)\end{array}$ & Chi Square \\
\hline Prescription of methotrexate & $93.3 \%(n=153 / 161)$ & $90.32 \%(n=84 / 161)$ & NS \\
\hline Average length of service (years) & 18.2 & 19.9 & $\mathrm{P}=0.02$ \\
\hline Analyse population & $\begin{array}{l}\text { Hospital/mixed practice } \\
(n=153)\end{array}$ & $\begin{array}{l}\text { Private practice } \\
(\mathrm{n}=\mathbf{8 4})\end{array}$ & Chi square \\
\hline Average length of service (years) & 18.2 & 19.9 & $\mathrm{P}=0.02$ \\
\hline $\begin{array}{l}\text { Systemic treatment line in which methotrexate is prescribed } \\
\text { - Ist line } \\
\text { - 2nd line } \\
\text { - 3rd line } \\
\text { - 4th line }\end{array}$ & $\begin{array}{l}69.93 \%(n=107) \\
23.5 \%(n=36 /) \\
6.5 \%(n=10) \\
0 \%(n=0)\end{array}$ & $\begin{array}{l}33.3 \%(n=28) \\
39.3 \%(n=33) \\
25 \%(n=21) \\
2.4 \%(n=2)\end{array}$ & $p=0.001$ \\
\hline Carrying out a test dose at initiation & $19.6 \%(n=30)$ & $19 \%(n=16)$ & NS \\
\hline $\begin{array}{l}\text { How methotrexate is administered } \\
\text { - Per os } \\
\text { - Subcutaneous pen } \\
\text { - Subcutaneous syringe } \\
\text { - Intramuscular }\end{array}$ & $\begin{array}{l}52.2 \% \\
40 \% \\
7.4 \% \\
0.3 \%\end{array}$ & $\begin{array}{l}59.4 \% \\
29 \% \\
11 \% \\
0.6 \%\end{array}$ & $\begin{array}{l}\text { NS } \\
p=0.007 \\
\text { NS } \\
\text { NS }\end{array}$ \\
\hline $\begin{array}{l}\text { Percentage of patients who are autonomous in carrying out } \\
\text { injections }\end{array}$ & $69.4 \%$ & $58.2 \%$ & $p=0.04$ \\
\hline $\begin{array}{l}\text { Initiation dosage of methotrexate } \\
-<15 \mathrm{mg} / \text { week } \\
-\geq 15 \mathrm{mg} / \text { week }\end{array}$ & $\begin{array}{l}21 \%(n=32) \\
79 \%(n=121)\end{array}$ & $\begin{array}{l}52.4 \%(n=40) \\
47.6 \%(n=44)\end{array}$ & $\mathrm{p}<0.001$ \\
\hline $\begin{array}{l}\text { Time frame for evaluating the effectiveness of methotrexate } \\
\text { - }<6 \text { weeks } \\
\text { - } 6 \text { to } 8 \text { weeks } \\
\text { - } \geq 10 \text { weeks }\end{array}$ & $\begin{array}{l}4.6 \%(n=7) \\
11.1 \%(n=17) \\
84.3 \%(n=129)\end{array}$ & $\begin{array}{l}16.7 \%(n=14) \\
15.4 \%(n=13) \\
67.9 \%(n=57)\end{array}$ & $\mathrm{p}<0.003$ \\
\hline $\begin{array}{l}\text { Dose adjustment level used } \\
\text { - } 2.5 \mathrm{mg} / \text { week } \\
\text { - } 5 \mathrm{mg} / \text { week } \\
\text { - Others }\end{array}$ & $\begin{array}{l}47.1 \%(n=72) \\
50.3 \%(n=77) \\
2.6 \%(n=4)\end{array}$ & $\begin{array}{l}69 \%(n=58) \\
26.2 \%(n=22) \\
4.8 \%(n=4)\end{array}$ & $\mathrm{p}<0.00 \mathrm{I}$ \\
\hline $\begin{array}{l}\text { Reasons for switching from an oral to an injectable form } \\
\text { - Poor tolerance } \\
\text { - Lack of efficacy } \\
\text { - Lack of compliance }\end{array}$ & $\begin{array}{l}91 \% \\
43.9 \%(n=61) \\
35.2 \%(n=49) \\
20.9 \%(n=29)\end{array}$ & $\begin{array}{l}76 \% \\
57.8 \%(n=37) \\
34.4 \%(n=22) \\
7.8 \%(n=5)\end{array}$ & $\begin{array}{l}\mathrm{P}<0.001 \\
\mathrm{P}=0.004\end{array}$ \\
\hline Concomitant prescription of folic acid & $98.9 \%$ & $98.3 \%$ & NS \\
\hline Prescription test for the evaluation of hepatic fibrosis & $77.8 \%(n=119)$ & $82.1 \%(n=69)$ & $\mathrm{p}<0.001$ \\
\hline
\end{tabular}

Abbreviation: NS, not significant.

they benefit from therapeutic education by paramedical staff. Dermatologists in private practice, on the other hand, carry out more tests to monitor risk to the liver. We have assessed whether the date of graduation has an impact, it does not for the prescription of methotrexate, test dose or fibrosis test, only the initiation dose is different.

The limitations of this study are the declarative nature of the data and the method of recruitment of the 
dermatologists questioned as they all participate in a network dedicated to chronic inflammatory dermatoses.

\section{Conclusion}

The results of our study show that methotrexate is used by the majority of dermatologists interviewed for moderate to severe psoriasis in adults. We highlighted heterogeneity in prescription modalities depending on the mode of practice (hospital based or private) but not the years of experience.

\section{Disclosure}

Funding source: Nordic Pharma laboratory. Dr Anne-Claire Fougerousse report grants from NORDIC Pharma, during the conduct of the study; Dr Josiane Parier reports personal fees from Medac, personal fees from Janssen, personal fees from Novartis, personal fees from Amgen, personal fees from Leo Pharma, outside the submitted work.

The authors report no other conflicts of interest in this work.

\section{References}

1. Richard MA, Corgibet F, Beylot-Barry M, et al. Sex- and age-ajusted prevalence estimates of five chronic inflammatory skin diseases in France: results of the OBJECTIFS PEAU study. $J$ Eur Acad Dermatol Venereol. 2018;32:1967-1971. doi:10.1111/jdv.14959

2. Mrowietz U, Kragballe K, Reich K, et al. Definition of treatment goals for moderate to severe psoriasis: a European consensus. Arch Dermatol Res. 2011;303(1):1-10. doi:10.1007/s00403-010-1080-1

3. Amatore F, Villani AP, Tauber M, Viguier M, Guillot B; Psoriasis Research Group of the French Society of Dermatology (Groupe de Recherche sur le Psoriasis de la Société Française de Dermatologie). French guidelines on the use of systemic treatments for moderate-tosevere psoriasis in adults. J Eur Acad Dermatol Venereol. 2019;33 (3):464-483. doi:10.1111/jdv. 15340

4. Gyulai R, Bagot M, Griffiths CEM, et al. Current practice of méthotrexate use for psoriasis: results of a worldwide survey among dermatologists. J Eur Acad Dermatol Venereol. 2015;29 (2):224-231. doi:10.1111/jdv.12495
5. Mazzuoccolo LD, Luna PC, Marciano S, et al. Real world prescription trends of méthotrexate for psoriasis in Argentina: results of a national survey. $J$ Dermatolog Treat. 2017;28(7):631-634. doi:10.1080/09546634.2017.1329503

6. Menting SP, Dekker PM, Limpens J, Hooft L, Spuls PI. Methotrexate dosing regimen for plaque-type psoriasis: a systematic review of the use of test-dose, start-dose, dosing scheme, dose adjustments, maximum dose and folic acid supplementation. Acta Derm Venereol. 2016;96(1):23-28. doi:10.2340/00015555-2081

7. Menter A, Gelfand JM, Connor C, et al. Joint American Academy of Dermatology-National Psoriasis Foundation guidelines of care for the management of psoriasis with systemic nonbiologic therapies. $J \mathrm{Am}$ Acad Dermatol. 2020;82(6):1445-1486. doi:10.1016/j.jaad.20 20.02.044

8. Tournier A, Khemis A, Maccari F, et al. Methotrexate efficacy and tolerance in plaque psoriasis. A prospective real-life multicentre study in France. Ann Dermatol Venereol. 2019;146(2):106-114. doi:10.1016/j.annder.2018.11.011

9. Reich K, Sorbe C, Griese L, Reich JLK, Augustin M. The value of subcutaneous vs. oral méthotrexate: real-world data from the German psoriasis registry PsoBest. Br J Dermatol. 2020. doi:10.1111/ bjd. 19690 .

10. Warren RB, Weatherhead SC, Smith CH, et al. British Association of Dermatologists' guidelines for the safe and effective prescribing of methotrexate for skin disease 2016. Br J Dermatol. 2016;175 (1):23-44. doi:10.1111/bjd.14816

11. Montaudié H, Sbidian E, Paul C, et al. Methotrexate in psoriasis: a systematic review of treatment modalities, incidence, risk factors and monitoring of liver toxicity. J Eur Acad Dermatol Venereol. 2011;25(Suppl 2):12-18. doi:10.1111/j.1468-3083.2011.03991.x

12. Maybury CM, Jabbar-Lopez ZK, Wong T, Dhillon AP, Barker JN, Smith $\mathrm{CH}$. Methotrexate and liver fibrosis in people with psoriasis: a systematic review of observational studies. $\mathrm{Br} J$ Dermatol. 2014;171(1):17-29. doi:10.1111/bjd.12941

13. Fougerousse AC, Perrussel M, Bécherel PA, et al. Systemic or biologic treatment in psoriasis patients does not increase the risk of a severe form of COVID-19. J Eur Acad Dermatol Venereol. 2020;34 (11):e676-e679. doi:10.1111/jdv.16761

14. Chiricozzi A, Gisondi P, Bellinato F, Girolomoni G. Immune response to vaccination in patients with psoriasis treated with systemic therapies. Vaccines (Basel). 2020;8(4):769. doi:10.3390/ vaccines 8040769
Clinical, Cosmetic and Investigational Dermatology

\section{Publish your work in this journal}

Clinical, Cosmetic and Investigational Dermatology is an international, peer-reviewed, open access, online journal that focuses on the latest clinical and experimental research in all aspects of skin disease and cosmetic interventions. This journal is indexed on CAS.
Dovepress

The manuscript management system is completely online and includes a very quick and fair peer-review system, which is all easy to use. Visit http://www.dovepress.com/testimonials.php to read real quotes from published authors. 